\title{
Polymerization of Hydrolysis Products of Methyltriethoxysilane in Aqueous Solutions
}

\author{
Isao HASEGAWA, Sumio SAKKA, Yoshiyuki SUGAHARA*, Kazuyuki KURODA* \\ and Chuzo KATO* \\ $\left(\begin{array}{l}\text { Institute for Chemical Research, Kyoto University, Gokasho, Uji-shi, Kyoto } 611 \\ \text { * Department of Applied Chemistry, School of Science and Engineering, Waseda University, } \\ \text { 3-4-1, Ohkubo, Shinjuku-ku, Tokyo } 169\end{array}\right.$
}

水溶液中におけるメチルトリエトキシシランの加水分解物の重合

長谷川功・作花済夫・菅原義之*・黒田一幸* ·加藤忠蔵*

( 京都大学化学研究所, 611 京都府宇治市五ヶ庄

* 早稲田大学理工学部応用化学科, 169 東京都新宿区大久保 3-4-1)

\begin{abstract}
The structure and distribution of chemical species of hydrolysis and polycondensation products of methyltriethoxysilane in aqueous solutions containing sodium ions have been studied with the trimethylsilylation technique and by ${ }^{29}$ Si n. m. r. spectroscopy. 11 trimethylsilylated derivatives of the products were obtained from the solutions. The recovery of methyltrisilanol $\left(\mathrm{CH}_{3} \mathrm{Si}(\mathrm{OH})_{3}\right)$ was much higher than that of the monosilicic acid in an aqueous sodium silicate solution at the same Si concentration and the same sodium ion-to-silicon molar ratio, suggesting that the polymerization of silicate anions is easier than that of hydrolysis products of methyltriethoxysilane in aqueous solutions. On the basis of the distribution, assignment of ${ }^{29} \mathrm{Si}$ $n . m . r$. peaks corresponding to low-molecular weight species formed from methyltriethoxysilane has been discussed.
\end{abstract}

[Received March 6, 1990 ; Accepted April 13, 1990]

\section{Key-words : Methyltriethoxysilane, Hydrolysis, Polymerization, Trimethylsilylation, ${ }^{29}$ Si n.m.r. spectroscopy}

\section{Introduction}

Trifunctional alkoxysilanes, $\mathrm{R}^{1} \mathrm{Si}\left(\mathrm{OR}^{2}\right)_{3}$, where $\mathrm{R}^{1}$ is an alkyl or aryl group and $\mathrm{R}^{2}$ is an alkyl group, have been used as raw materials for preparation of polyhedral or ladder-like organylsilsesquioxanes. ${ }^{1-4)}$ Recently, they are also noted as starting materials for producing ceramics, such as silica fibers and silicon carbide powders through the sol-gel processing. ${ }^{5)-8)}$ Since the structures would affect the properties of precursors and resultant materials, it is necessary to investigate structures of hydrolysis and polycondensation products of trifunctional silanes.

It is known that the polymerization of silicate anions in aqueous solutions is affected by various factors, such as the $\mathrm{SiO}_{2}$ concentration, the nature of coexisting cations, the cation-to-silica molar ratio, the $\mathrm{pH}$ and the temperature. So far, trimethylsilylation ${ }^{9)-13)}$ and ${ }^{29} \mathrm{Si} \mathrm{n.} \mathrm{m.} \mathrm{r.} \mathrm{spectros-}$ copy ${ }^{14)-17}$ have successfully been utilized to investigate the structure and distribution of silicate species in solutions. It is expected that these methods would be applicable to the study on hydrolysis and polycondensation products of trifunctional alkoxysilanes present in solutions as well.

In this study, methyltriethoxysilane $\left(\mathrm{CH}_{3} \mathrm{Si}\right.$ $\left.\left(\mathrm{OC}_{2} \mathrm{H}_{5}\right)_{3}\right)$ has been selected as a trifunctional alkoxysilane in order to obtain basic information on the structure and distribution of the hydrolysis and polycondensation products in aqueous solutions containing sodium ions. First, the structure and distribution have been investigated with the trimethylsilylation technique combined with gasliquid and gel permeation chromatographies. It was demonstrated that trimethylsilylation by the method of Lentz was adaptable to the investigation on species formed by hydrolysis and polymerization of methyltriethoxysilane in solutions. ${ }^{18)}$ Then, on the basis of the trimethylsilylation study, assignment of signals on ${ }^{29} \mathrm{Si} \mathrm{n}$. m.r. spectra of the solutions has been discussed. Although assignment of the signals to each structure unit of methylsilsesquioxanes has been described in Ref. 19, that to each low-molecular weight species has not been reported. 


\subsection{Materials}

\section{Experimental}

$5.0 \mathrm{~mol} \mathrm{dm}{ }^{-3}$ aqueous sodium hydroxide solution, methyltriethoxysilane, conc. hydrochloric acid and 2-propanol of reagent grade were used. Hexamethyldisiloxane (bp $100^{\circ} \mathrm{C}$ ) and tetrahydrofuran $\left(\mathrm{bp} 88^{\circ} \mathrm{C}\right)$ were used after distillation. Amberlyst 15 cation-exchange resin was used after drying.

\subsection{Preparation of solutions}

A given amount of methyltriethoxysilane was added to an aqueous sodium hydroxide solution whose concentration had been adjusted by adding deionized water to $5.0 \mathrm{~mol} \mathrm{dm}{ }^{-3}$ aqueous sodium hydroxide solution. The mixture was stirred for 2 days at room temperature to hydrolyze methyltriethoxysilane and obtain a homogeneous solution in which an equilibrium among species formed from methyltriethoxysilane has been established. In this manner, solutions were prepared whose $\mathrm{Na} / \mathrm{Si}$ ratio (the molar ratio of sodium ions to silicon) was fixed at 1.0. The Si

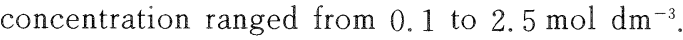

\subsection{Trimethylsilylation}

A $1 \mathrm{~cm}^{3}$ portion of each solution was trimethylsilylated by the method of Lentz. ${ }^{9}$ The conditions on the trimethylsilylation, gas-liquid chromatography and combined gas chromatograph-mass spectrometry were all the same as those described previously. ${ }^{18)}$

Since standard substances for trimethylsilylated derivatives of hydrolysis and polycondensation products of methyltriethoxysilane except for the monomer $\left(\mathrm{CH}_{3} \mathrm{SiO}_{3}{ }^{3-}\right)$ could not be obtained, the distribution of the species was expressed in terms of percentages of the total peak area on a gas chromatogram. The trimethylsilylated derivative of the monomer, $\mathrm{CH}_{3} \mathrm{SiO}_{3}[\mathrm{Si}$ $\left.\left(\mathrm{CH}_{3}\right)_{3}\right]_{3}$, could be obtained by treating methyltriethoxysilane with Amberlyst 15 cation-exchange resin in an excess of hexamethyldi- siloxane. ${ }^{20)}$ Quantitative analysis for the monomer was performed by using hexadecane as an internal standard.

Gel permeation chromatography was performed with a Shimadzu LC-6 A equipped with an Asahipack GS $-310 \mathrm{H}$ column (length : $250 \mathrm{~mm}$, i. d. : $7.6 \mathrm{~mm}$ ). The mobile phase was tetrahydrofuran, which was flowed at a rate of $0.2 \mathrm{~cm}^{3} \mathrm{~min}^{-1}$.

\section{$2.4{ }^{29} \mathrm{Si} \mathrm{n.m.r}$. spectroscopy}

${ }^{29} \mathrm{Si} \mathrm{n}$. m. r. spectra were obtained at $79.42 \mathrm{MHz}$ with a JEOL GSX-400 spectrometer, using a pulse angle of $45^{\circ}$, a delay time of $5 \mathrm{~s}$ and an acquisition time of $0.084 \mathrm{~s}$. For obtaining the spectra, the solutions containing $10 \% \mathrm{v} / \mathrm{v} \mathrm{D}_{2} \mathrm{O}$ were prepared to provide a deuterium field/ frequency lock signal and 100 transients were used. Chemical shifts are given with reference to tetramethylsilane.

In order to describe the nature of a silicon atom in a hydrolysis and polycondensation product of methyltriethoxysilane, all of the structural units are described as $\mathrm{T}$, since coordination is to three oxygen atoms. The number of siloxy bridges involved in that coordination is given as a superscript. The degree of protonation is ignored. Thus, $\mathrm{T}^{0}$ denotes the monomer, $\mathrm{CH}_{3} \mathrm{SiO}_{3}{ }^{3-}$, or its protonated forms. $\mathrm{T}^{1} \mathrm{~T}^{1}$ indicates the dimeric species, $\mathrm{T}^{1} \mathrm{~T}^{2} \mathrm{~T}^{1}$ the linear trimer, and so on.

\section{Results and discussion}

Figure 1 shows a gas chromatogram of the trimethylsilylated derivatives obtained from an aqueous solution of hydrolysis and polycondensation products of methyltriethoxysilane under the presence of sodium ions at a $\mathrm{Na} / \mathrm{Si}$ ratio of 1.0 and a Si concentration of $2.0 \mathrm{~mol} \mathrm{dm}{ }^{-3}$. The peaks which appear on the gas chromatogram are assigned by conducting combined gas chromatograph-mass spectrometry. The mass spectra of the compounds corresponding to these peaks show

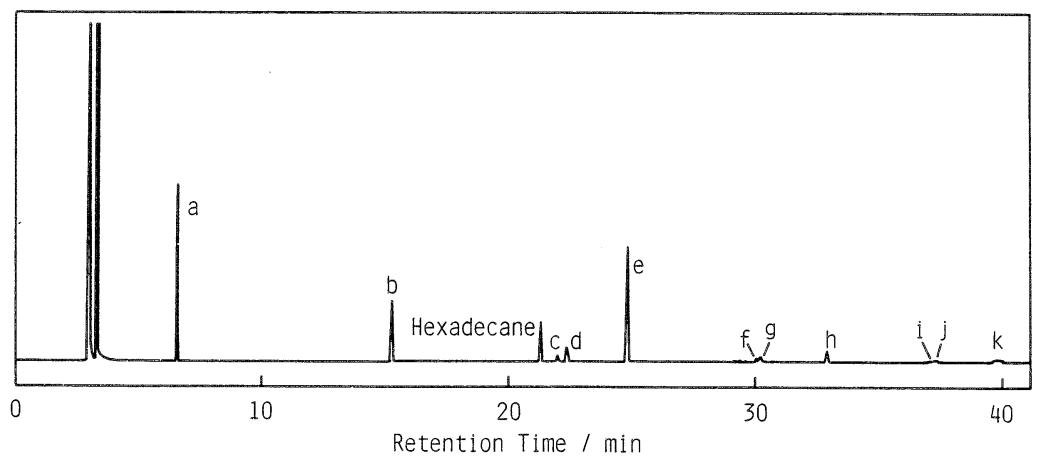

Fig. 1. Gas chromatogram of the trimethylsilylated derivatives obtained from an aqueous solution of hydrolysis and polycondensation products of methyltriethoxysilane under the presence of sodium ions at a $\mathrm{Na} / \mathrm{Si}$ ratio of 1.0 and a $\mathrm{Si}$ concentration of $2.5 \mathrm{~mol} \mathrm{dm} \mathrm{dm}^{-3}$. 
the characteristics seen in the trimethylsilylated derivatives of silicates ; ${ }^{211}$ the molecular ion is either of very low abundance or below detection limit, and the most structurally informative ion is the one produced by the loss of a methyl radical from the molecular ion, and the ion at $\mathrm{m} / \mathrm{e} 73$, which is due to $\left[\mathrm{Si}\left(\mathrm{CH}_{3}\right)_{3}\right]^{+}$, or at $\mathrm{m} / \mathrm{e} 147$, which is due to $\left[\left(\mathrm{CH}_{3}\right)_{3} \mathrm{SiOSi}\left(\mathrm{CH}_{3}\right)_{2}\right]^{+}$, is present. The peaks $a, b, d, e$, and $h$ have been identified in the previous study, $\left.{ }^{18}\right)$ and other six peaks are assigned, as shown in Table 1. The peaks $c$ and $d, f$ and $g, i$ and $j$ show almost the same mass spectra, suggesting that the compounds corresponding to the respective sets of the peaks are isomers.

Figure 2 shows the variations in the peak area ratios of the trimethylsilylated derivatives of

Table 1. Assignment of the peaks on the gas chromatogram shown in Fig. 1

\begin{tabular}{lll}
\hline Peak & Formulae & Molecular weight \\
\hline a & $\mathrm{CH}_{3} \mathrm{SiO}_{3}\left[\mathrm{Si}\left(\mathrm{CH}_{3}\right)_{3}\right]_{3}$ & 310 \\
b & $\left(\mathrm{CH}_{3}\right)_{2} \mathrm{Si}_{2} \mathrm{O}_{5}\left[\mathrm{Si}\left(\mathrm{CH}_{3}\right)_{3}\right]_{4}$ & 458 \\
C & $\left(\mathrm{CH}_{3}\right)_{4} \mathrm{Si}_{4} \mathrm{O}_{8}\left[\mathrm{Si}\left(\mathrm{CH}_{3}\right)_{3}\right]_{4}$ & 592 \\
d & $\left(\mathrm{CH}_{3}\right)_{4} \mathrm{Si}_{4} \mathrm{O}_{8}\left[\mathrm{Si}\left(\mathrm{CH}_{3}\right)_{3}\right]_{4}$ & 592 \\
e & $\left(\mathrm{CH}_{3}\right)_{3} \mathrm{Si}_{3} \mathrm{O}_{7}\left[\mathrm{Si}\left(\mathrm{CH}_{3}\right)_{3}\right]_{5}$ & 606 \\
f & $\left(\mathrm{CH}_{3}\right)_{5} \mathrm{Si}_{5} \mathrm{O}_{10}\left[\mathrm{Si}\left(\mathrm{CH}_{3}\right)_{3}\right]_{5}$ & 740 \\
$\mathrm{~g}$ & $\left(\mathrm{CH}_{3}\right)_{5} \mathrm{Si}_{5} \mathrm{O}_{10}\left[\mathrm{Si}\left(\mathrm{CH}_{3}\right)_{3}\right]_{5}$ & 740 \\
$\mathrm{~h}$ & $\left(\mathrm{CH}_{3}\right)_{4} \mathrm{Si}_{4} \mathrm{O}_{9}\left[\mathrm{Si}\left(\mathrm{CH}_{3}\right)_{3}\right]_{6}$ & 754 \\
i & $\left(\mathrm{CH}_{3}\right)_{6} \mathrm{Si}_{6} \mathrm{O}_{12}\left[\mathrm{Si}\left(\mathrm{CH}_{3}\right)_{3}\right]_{6}$ & 888 \\
j & $\left(\mathrm{CH}_{3}\right)_{6} \mathrm{Si}_{6} \mathrm{O}_{12}\left[\mathrm{Si}\left(\mathrm{CH}_{3}\right)_{3}\right]_{6}$ & 888 \\
$\mathrm{k}$ & $\left(\mathrm{CH}_{3}\right)_{5} \mathrm{Si}_{5} \mathrm{O}_{11}\left[\mathrm{Si}\left(\mathrm{CH}_{3}\right)_{3}\right]_{7}$ & 902 \\
\hline
\end{tabular}

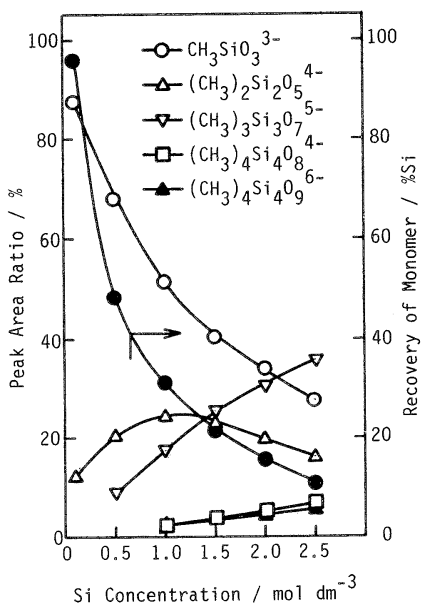

Fig. 2. Variations in the peak area ratios of the trimethylsilylated derivatives of hydrolysis and polycondensation products of methyltriethoxysilane and the recovery of the monomer with the Si concentration in aqueous solutions of the products containing sodium ions at a $\mathrm{Na} / \mathrm{Si}$ ratio of 1.0 . hydrolysis and polycondensation products of methyltriethoxysilane and the recovery of the monomer with the $\mathrm{Si}$ concentration in aqueous solutions of the products containing sodium ions at a $\mathrm{Na} / \mathrm{Si}$ ratio of 1.0 . The compounds corresponding to the peaks $\mathrm{c}, \mathrm{f}, \mathrm{g}, \mathrm{i}, \mathrm{j}$, and $\mathrm{k}$ are just traced in small peak areas (all under $4.0 \%$ in the peak area ratio at the maximum) and so the peak area ratios of these compounds are not shown in the figure. With the increase of the Si concentration, the peak area ratio of the monomer decreases and those of the linear trimer $\left(\left(\mathrm{CH}_{3}\right)_{3} \mathrm{Si}_{3} \mathrm{O}_{7}{ }^{5-}\right)$ and higher molecular weight species increase. That of the dimer $\left(\left(\mathrm{CH}_{3}\right)_{3} \mathrm{Si}_{2} \mathrm{O}_{5}{ }^{5-}\right)$ increases at the $\mathrm{Si}$

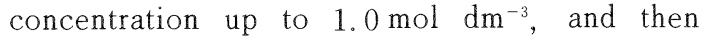
decreases with increasing $\mathrm{Si}$ concentration. These indicate that the polymerization of hydrolysis products of methyltriethoxysilane proceeds as the $\mathrm{Si}$ concentration increases. The peak area ratio of $\left(\mathrm{CH}_{3}\right)_{3} \mathrm{Si}_{3} \mathrm{O}_{7}{ }^{5-}$ is fairly high at a $\mathrm{Si}$ concentration of $2.5 \mathrm{~mol} \mathrm{dm}^{-3}$. The fact that the peak area ratios of higher molecular weight species than $\left(\mathrm{CH}_{3}\right)_{3} \mathrm{Si}_{3} \mathrm{O}_{7}{ }^{5-}$ increase with increasing $\mathrm{Si}$ concentration indicates, however, that the species must be formed in the course of random polymerization of hydrolysis products of methyltriethoxysilane and is not formed selectively.

In silicate solutions containing alkali metal cations, the polymerization of silicate species takes place at random, which leads to the presence of a variety of silicate anions with different structures. ${ }^{91-17)}$ This fact suggests that both silicate anions and hydrolysis products of methyltriethoxysilane polymerize randomly in aqueous solutions containing sodium ions. Comparison with the variation in the recovery of the monosilicic acid $\left(\mathrm{SiO}_{4}{ }^{4-}\right)$ with the $\mathrm{Si}$ concentration in sodium silicate solutions prepared by hydrolyzing tetraethoxysilane in aqueous sodium hydroxide solutions at a $\mathrm{Na} / \mathrm{Si}$ ratio of $1.0^{13)}$ indicates, however, that the recovery of $\mathrm{CH}_{3} \mathrm{SiO}_{3}{ }^{3-}$ is much higher than that of $\mathrm{SiO}_{4}{ }^{4-}$ at the same $\mathrm{Si}$ concentration. For example, the recovery of $\mathrm{CH}_{3} \mathrm{SiO}_{3}{ }^{3-}$ is $31.2 \%$ and that of $\mathrm{SiO}_{4}{ }^{4-}$ is $3.4 \%$ at a Si concentration of $1.0 \mathrm{~mol} \mathrm{dm}{ }^{-3}$. This suggests that the polymerization of silicate anions is easier than that of hydrolysis products of methyltriethoxysilane, which might be attributed to the difference in the functionality of silane, or to the repulsion of methyl groups in the products from methyltriethoxysilane.

Figure 3 shows gel permeation chromatograms of the trimethylsilylated derivatives obtained from the aqueous solutions at Si concentrations of (a) 0.1 and (b) $2.5 \mathrm{~mol} \mathrm{dm}^{-3}$. The peak on the chromatogram shown in Fig. 3(a) is assigned to 


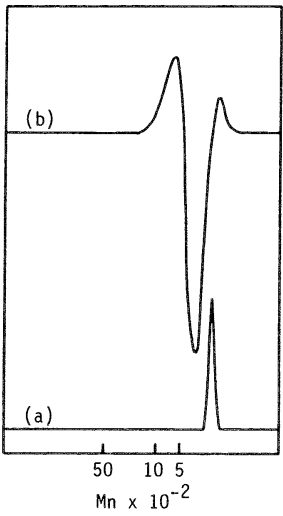

Fig. 3. Gel permeation chromatograms of the trimethylsilylated derivatives obtained from aqueous solutions of hydrolysis and polycondensation products of methyltriethoxysilane under the presence of sodium ions at a Na/Si ratio of 1.0 and Si concentrations of (a) 0.1 and (b) $2.5 \mathrm{~mol} \mathrm{dm} \mathrm{dm}^{-3}$.

the monomer, $\mathrm{CH}_{3} \mathrm{SiO}_{3}\left[\mathrm{Si}\left(\mathrm{CH}_{3}\right)_{3}\right]_{3}$. Peaks of polymeric species with the molecular weight higher than $c a .10^{3}$ are not seen on the chromatogram shown in Fig. 3(b), indicating that polymeric species are hardly present even when the Si concentration is increased to $2.5 \mathrm{~mol} \mathrm{dm}^{-3}$. This fact also suggests that the polymerization of hydrolysis products of methyltriethoxysilane in aqueous solutions containing sodium ions does not proceed to form high-molecular weight species.

Figure 4 shows ${ }^{29} \mathrm{Si} \mathrm{n}$. m. r. spectra of aqueous solutions of hydrolysis and polycondensation products of methyltriethoxysilane at a $\mathrm{Na} / \mathrm{Si}$ ratio of 1.0 and Si concentrations of (a) 0.1 , (b) 0.5 , (c) 1.0 , (d) 1.5 , and (e) $2.0 \mathrm{~mol} \mathrm{dm}{ }^{-3}$. Four bands labeled A, B, C, and D in Fig. 4(e) are observed. On the basis of previous studies, ${ }^{19), 22 \text {-27) }}$ band $A$ is assigned to the $T^{0}$ unit, band $B$ to the $T^{1}$ unit, and band $\mathrm{D}$ to the $\mathrm{T}^{2}$ unit.

From the trimethylsilylation study on the aqueous solutions described above, it has been found that methyltrisilanol and a small amount of the dimer are solely present in the solution at a $\mathrm{Si}$ concentration of $0.1 \mathrm{~mol} \mathrm{dm}{ }^{-3}$. On ${ }^{29} \mathrm{Si} \mathrm{n} . \mathrm{m} . \mathrm{r}$. spectrum of the solution shown in Fig. 4(a), two peaks, an.intensive peak at -41.2 p.p.m. and a weak peak at -49.6 p. p. m., appear. Since it has been found that about $93 \%$ of silicon component in the solution is present as the monomer, the peak at -41.2 p.p.m. may be assigned to methyltrisilanol, and the peak at -49.6 p.p.m. to the end group of the dimer. Only one signal should be observed for the dimer, as the dimer consists of two equivalent $T^{1}$ units.

On ${ }^{29} \mathrm{Si}$ n. m.r. spectra of partially and fully

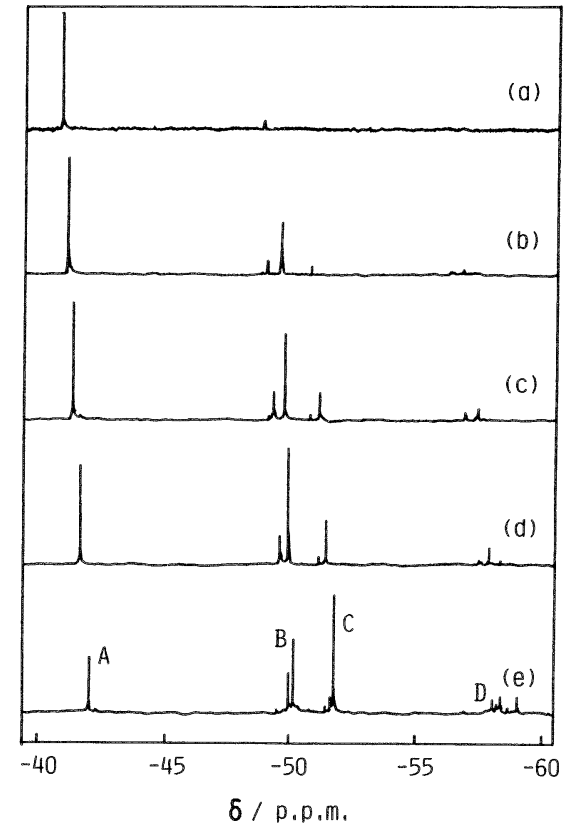

Fig. 4. $79.42 \mathrm{MHz}{ }^{29} \mathrm{Si}$ n.m.r. spectra of aqueous solutions of hydrolysis and polycondensation products of methyltriethoxysilane under the presence of sodium ions at a $\mathrm{Na} / \mathrm{Si}$ ratio of 1.0 and $\mathrm{Si}$ concentrations of (a) 0.1 , (b) 0.5 , (c) 1.0 , (d) 1.5 , and (e) $2.0 \mathrm{~mol} \mathrm{dm}^{-3}$.

hydrolyzed products of tetramethoxy- or ethoxysilane, peaks shift to higher frequency when the degree of hydrolysis of tetraalkoxysilane increases, in other words, the number of hydroxyl groups which displace for alkoxyl groups increases. ${ }^{28) 29)}$ For example, Pouxviel et al. ${ }^{29)}$ reported that the resonance due to $\mathrm{Si}\left(\mathrm{OC}_{2} \mathrm{H}_{5}\right)_{4}$ appears at -82.0 p.p.m., that due to $\mathrm{Si}\left(\mathrm{OC}_{2} \mathrm{H}_{5}\right)_{3}$. $(\mathrm{OH})$ at -78.9 p.p.m., that due to $\operatorname{Si}\left(\mathrm{OC}_{2} \mathrm{H}_{5}\right)_{2}$ $(\mathrm{OH})_{2}$ at -76.2 p.p.m., that due to $\mathrm{Si}\left(\mathrm{OC}_{2} \mathrm{H}_{5}\right)$. $(\mathrm{OH})_{3}$ at -74.2 p. p. m. , and that due to $\mathrm{Si}(\mathrm{OH})_{4}$ at -72.4 p.p.m. The value of the chemical shift of $\mathrm{CH}_{3} \mathrm{Si}\left(\mathrm{OC}_{2} \mathrm{H}_{5}\right)_{3}$ is measured to be -42.38 p.p.m. In addition, there is enough amount of water in the solution for hydrolyzing methyltriethoxysilane completely. These facts suggest that the peak at -41.2 p. p. m. may be assigned to the completely hydrolyzed product of methyltriethoxysilane, $\mathrm{CH}_{3} \mathrm{SiO}_{3}{ }^{3-}$.

Peaks at -49.0 p.p. m. in band $B$ and -56.7 p. p. m. in band D, which are the third and fourth intensive peaks on the ${ }^{29} \mathrm{Si} \mathrm{n} . \mathrm{m}$. r. spectrum of the solution at $0.5 \mathrm{~mol} \mathrm{dm}^{-3}$, may be attributed to the linear trimeric species. Because it has been found that the linear trimer is the third dominant species in the solution at $0.5 \mathrm{~mol} \mathrm{dm}^{-3}$ from the trimethylsilylation study. In addition, since the linear trimer consists of two $T^{1}$ units and one $T^{2}$ unit, the ratio of intensities of peaks in bands $B$ and $D$ 
should be $2: 1$. Actually, the ratio of the intensity of the peak at -49.0 p.p.m. and that at 56.7 p. p. m. is almost $2: 1$, and this ratio does not change in the solutions at different $\mathrm{Si}$ concentrations.

If band $\mathrm{C}$ is also assigned to the end group, $\mathrm{T}^{1}$ units, the total intensity in bands $\mathrm{B}$ and $\mathrm{C}$ is too large to be explained by end groups alone, suggesting that band $\mathrm{C}$ may not be ascribed to $\mathrm{T}^{1}$ units. On the cyclization of species consisting of siloxane bonds, the resonance due to middle groups in the species having the cyclic trimeric structure appears at a higher frequency from that due to middle groups in the species with the linear structure. ${ }^{22), 24)}$ It was reported that the shift for dimethylsiloxane was about 14 p.p.m. and that for silicate species was about 6 p.p.m. The difference in the values of chemical shifts of bands $\mathrm{C}$ and $\mathrm{D}$ is about 6 p.p.m. from Fig. 4. Therefore, band $\mathrm{C}$ may tentatively be assigned to the middle group of the cyclic trimer, although the trimethylsilylated derivative has not been able to be recovered from the solutions.

The fact that the trimethylsilylated derivative of the cyclic trimeric species has not been able to be obtained from the solutions may be attributed to destruction of the species by side reactions during trimethylsilylation. It was reported that side reactions during trimethylsilylation of silicate solutions by the method of Lentz destroyed the species which had the cyclic trimeric structure. ${ }^{301}$

From these facts, assignment of peaks observed on ${ }^{29} \mathrm{Si} \mathrm{n}$. m.r. spectra of aqueous solutions of hydrolysis and polycondensation products of methyltriethoxysilane under the presence of sodium ions is summarized in Table 2. Values of chemical shifts for the species vary with the Si concentration of the solutions, as is seen in Fig. 4. It appears that resonances move to lower frequencies with increasing $\mathrm{Si}$ concentration of the solutions. Although the degree of change differs with each structural unit of hydrolysis and polycondensation products of methyltriethoxy-

Table 2. Assignment of ${ }^{29} \mathrm{Si} \mathrm{n.m.r.} \mathrm{peaks} \mathrm{of} \mathrm{low-}$ molecular weight species formed by hydrolysis and polymerization of methyltriethoxysilane in aqueous solutions containin

\begin{tabular}{lcr}
\hline Species & Structural unit & $\delta / \mathrm{p} \cdot \mathrm{p} \cdot \mathrm{m}$. \\
\hline Monomer & $\mathrm{T}^{0}$ & $-40.9--42.1$ \\
Dimer & $\mathrm{T}^{1}$ & $-48.9--50.2$ \\
Linear trimer & $\mathrm{T}^{1}$ & $-49.0--50.0$ \\
& $\mathrm{~T}^{2}$ & $-56.8--58.4$ \\
Cyclic trimer & $\mathrm{T}^{2}$ & $-50.8--51.8$ \\
\hline
\end{tabular}

silane, the degree for a certain unit in a species seems to be almost in proportion to the $\mathrm{Si}$ concentration of the solutions.

In the trimethylsilylation study, the presence of isomers for $\left(\mathrm{CH}_{3}\right)_{4} \mathrm{Si}_{4} \mathrm{O}_{8}{ }^{4-},\left(\mathrm{CH}_{3}\right)_{5} \mathrm{Si}_{5} \mathrm{O}_{10}{ }^{5-}$, and $\left(\mathrm{CH}_{3}\right)_{6} \mathrm{Si}_{6} \mathrm{O}_{12}{ }^{6-}$ has been confirmed, suggesting that the species having the tri-branching unit, $\mathrm{CH}_{3} \mathrm{Si}\left(\mathrm{O}^{-}\right)_{3}$, should be present in the solutions with Si concentrations higher than $1.5 \mathrm{~mol} \mathrm{dm}^{-3}$. It was reported that peaks due to the tri-branching unit appeared around -65 p.p. m. ${ }^{19,22)-27)}$ In the present study, however, no such peaks can be observed, which may be due to low concentrations of the species having $\mathrm{T}^{3}$ units. The degree of polymerization of the hydrolysis products does not increase even in the solution high at $2.5 \mathrm{~mol}$ $\mathrm{dm}^{-3}$. And so, intensities of peaks due to other species than the monomer, dimer, and linear trimer are so weak that it is difficult to assign peaks due to higher molecular weight species on the ${ }^{29} \mathrm{Si} \mathrm{n} . \mathrm{m} . \mathrm{r}$. spectra in the present study. Further studies will be continued for complete interpretation of ${ }^{29} \mathrm{Si} \mathrm{n}$. m.r. peaks of hydrolysis and polycondensation products of methyltriethoxysilane.

\section{Summary}

The structure and distribution of hydrolysis and polycondensation products of methyltriethoxysilane present in aqueous solutions containing sodium ions have been investigated with the trimethylsilylation technique and by ${ }^{29} \mathrm{Si}$ n. m. r. spectroscopy. It has been found that the polymerization of hydrolysis products of methyltriethoxysilane in aqueous solutions containing sodium ions takes place randomly and a variety of the species with different structures is present. However, the degree of polycondensation of the species in the aqueous solutions at a certain $\mathrm{Si}$ concentration is much lower than that of silicate species, which may be attributed to the difference in the functionality of silane in the species formed from methyltriethoxysilane and silicate anions or the repulsion between methyl groups in the species from methyltriethoxysilane. In addition, ${ }^{29} \mathrm{Si}$ n. m. r. peaks due to the monomeric, dimeric, and linear and cyclic trimeric species consisting only of the $\mathrm{CH}_{3} \mathrm{SiO}_{3}{ }^{3-}$ unit have been assigned.

Acknowledgments This work was supported by a Grant-inAid for Scientific Research on Priority Areas, New Functionality Materials-Design, Preparation and Control, The Ministry of Education, Science and Culture, No. 62604011. The authors wish to express their sincere thanks to Mr. Chuu Nakamura of Science and Engineering Research Laboratory, Waseda University for recording mass spectra. 


\section{References}

1) M. M. Sprung and F. O. Guenther, J. Am. Chem. Soc, 77, 3990-96 (1955).

2) A. J. Barry, W. H. Daudt, J. J. Domicone and J.W. Gilkey, J. Am. Chem. Soc., 77, 4248-52 (1955).

3) L. H. Vogt, Jr. and J. F. Brown, Jr., Inorg. Chem., 2, 189-92 (1963).

4) M. G. Voronkov and V.I. Lavrent'yev, Top. Curr. Chem., 102, 199-236 (1982).

5) S. Sakka, Y. Tanaka and T. Kokubo, J. Non-Cryst. Solids, 82, 24-30 (1986).

6) D.A. White, S. M. Oleff, R. D. Boyer, P.A. Budinger and J.R. Fox, Adv. Ceram. Mater., 2, 45-52 (1987).

7) D. A. White, S. M. Oleff and J.R. Fox, Adv. Ceram. Mater. , 2, 53-59 (1987).

8) Y. Sugahara, Y. Takeda, K. Kuroda and C. Kato, J. Non-Cryst. Solids, 100, 542-46 (1988).

9) C. W. Lentz, Inorg. Chem., 3, 574-79 (1964).

10) L. S.D. Glasser, E.E. Lachowski and G. G. Cameron, J. Appl. Chem. Biotechnol., 27, 39-47 (1977).

11) L. S. D. Glasser and E. E. Lachowski, J. Chem. Soc., Dalton Trans., 1980, 393-98.

12) N. H. Ray and R. J. Plaisted, J. Chem. Soc., Dalton Trans., 1983, 475-81.

13) I. Hasegawa, K. Kuroda and C. Kato, Bull. Chem. Soc. Jpn. , 59, 2279-83 (1986).

14) G. Engelhardt, D. Zeigan, H. Jancke, D. Hoebbel and W. Wieker, Z. Anorg. Allg. Chem., 418, 17-28 (1975).

15) R. K. Harris and C. T. G. Knight, J. Chem. Soc, Faraday Trans. 2, 79, 1525-38 (1983).

16) R. K. Harris and C. T. G. Knight, J. Chem. Soc.,
Faraday Trans. 2, 79, 1539-61 (1983).

17) A. V. McCormick, A. T. Bell and C. J. Radke, Zeolites, 7, 183-90 (1987).

18) I. Hasegawa, S. Sakka, K. Kuroda and C. Kato, J. Chromatogr., 410, 137-43 (1987).

19) H. Marsmann, "NMR 17 Basic Principles and Progress, Oxygen-17 and Silicon-29", Edited by P. Diehl, E. Fluck and R. Kosfeld, Springer-Verlag, Berlin (1981) pp. 151-231.

20) I. Hasegawa and S. Sakka, J. Organomet. Chem., 340, 31-36 (1988)

21) F.F.H. Wu, J. Götz, W. D. Jamieson and C.R. Masson, J. Chromatogr., 48, 515-20 (1970).

22) G. Engelhardt, H. Jancke, M. Mägi, T. Pehk and E. Lippmaa, J. Organomet. Chem., 28, 293-300 (1971).

23) H. -G. Horn and H. C. Marsmann, Makromol. Chem., 162, 255-67 (1972).

24) G. Engelhardt, M. Mägi and E. Lippmaa, J. Organomet. Chem., 54, 115-22 (1973).

25) G. Engelhardt, H. Jancke, E. Lippmaa and A. Samoson, J. Organomet. Chem., 210, 295-301 (1981).

26) G. E. Maciel, M. J. Sullivan and D. W. Sindorf, Macromolecules. 14, 1607-08 (1981).

27) D.W. Sindorf and G. E. Maciel, J. Am. Chem. Soc., 105, 3767-76 (1983).

28) I. Artaki, M. Bradley, T.W. Zerda and J. Jonas, J. Phys. Chem., 89, 4399-404 (1985).

29) J.C. Pouxviel, J.P. Boilot, J. C. Beloeil and J.Y. Lallemand, J. Non-Cryst. Solids, 89, 345-60 (1987).

30) I. Hasegawa, S. Sakka, Y. Sugahara, K. Kuroda and C. Kato, J. Chem. Soc., Chem. Commun., 1989, 208-10. 